Recepción: 01 / 03/ 2018

Aceptación: 15 / 05 / 2018

Publicación: 29 / 09 / 2018

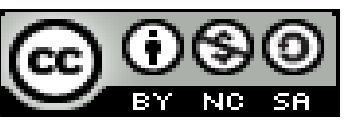

Ciencias de la salud

Artículo Científico

\title{
Infecciones vaginales en mujeres en edad fértil
}

\section{Vaginal infections in women of childbearingage}

\section{Infecções vaginais em mulheres em idade fértil}

Fabián Zambrano-Loor ${ }^{\mathrm{I}}$

Fabianzambrano12@hotmail.com

Nakin A. Veliz-Mero II

nakinvelizm@hotmail.com

María C. Guillen-Rivadeneira ${ }^{\text {III }}$

mariacguille@gmail.com

\author{
Ronald A. Eche-Salvatierra ${ }^{\text {IV }}$ \\ ronaldeche31@hotmail.com \\ Jorge R. Macías-Fernández ${ }^{\mathrm{V}}$ \\ josemacias_12@gmail.com \\ Tatiana A. Lino-Solís VI \\ Tatianalino_12@hotmail.com
}

I. Gineco-Obstetra; Diplomado en Ecografía General, Especialista en Planificación Estratégica; Docente de la Universidad Laica Eloy Alfaro de Manabí, Manta, Ecuador.

II. Doctor en Medicina y Cirugía; Magister en Gestión y Desarrollo Social, Magister en Gerencia en Salud para el Desarrollo Local, Director Distrito 13D02 Jaramijo - Manta - Montecristi - Salud, Docente Universidad Laica Eloy Alfaro de Manabí, Manta, Ecuador.

III. Médico Tratante Centro de Salud Santa Ana, Cuenca, Ecuador.

IV. Médico Cirujano, Especialista en Medicina Legal, Director del Hospital Básico Natalia Huerta de Niemes, Distrito 13D12 Tosagua, Rocafuerte, Portoviejo, Ecuador.

v. Magister en Gerencia en Salud para el Desarrollo Local, Medico General, Centro de Salud Pichincha - Distrito 13D08, Manta, Ecuador.

VI. Licenciada en Enfermería, Centro de Salud Rural Machalilla; Distrito 13D03 Jipijapa, Ecuador. 


\section{Resumen}

Se realizó una revisión sobre las infecciones del aparato genital femenino específicamente de vaginosis, cervicitis y enfermedad pelviana inflamatoria, patologías que en la actualidad constituyen un serio problema de salud pública, al ser uno de los principales motivos de consulta más frecuente en mujeres en edad fértil. La vaginosis bacteriana es un problema de salud ampliamente difundido, con múltiples connotaciones. Ha sido objeto de gran cantidad de estudios y trabajos desde hace décadas y aun en la actualidad sigue siendo una entidad polémica y de resultados contradictorios. La cervicitis es una de las afecciones más frecuentes en ginecología, llega a observarse en el $50 \%$ de las mujeres que han tenido parto, y muchas veces son el punto de partida de la infección hacia localizaciones más altas. En ésta existe una infección activa, generalmente extendida a la vagina y/o al cuerpo uterino, que puede ser causada por diferentes gérmenes. La enfermedad pélvica inflamatoria engloba a las infecciones del tracto genital superior femenino. La importancia del diagnóstico precoz y su tratamiento adecuado reside tanto por las complicaciones en la fase aguda como por las secuelas, que incluyen el dolor crónico y la esterilidad. Todas las infecciones del aparato genital femenino presentan una sintomatología que puede ser común, como disuria, polaquiuria, prurito vulvar, dispareunia y leucorrea. Resulta muy difícil distinguir dichas infecciones entre sí solo sobre la base de la sintomatología, siendo absolutamente necesario fundamentarse en la exploración y el estudio microbiológico para establecer el diagnóstico.

Palabras claves: Infecciones, Vaginosis bacteriana, Cervicitis mucopurulenta. Enfermedad pélvica inflamatoria. 


\section{Abstract}

A review was made on the infections of the female genital tract specifically of vaginosis, cervicitis and inflammatory pelvic disease, pathologies that currently constitute a serious public health problem, being one of the main reasons for more frequent consultation in women of childbearing age. Bacterial vaginosis is a widespread health problem with multiple connotations. It has been the subject of a large number of studies and works for decades and even today it remains a controversial entity with contradictory results. Cervicitis is one of the most frequent conditions in gynecology, it can be observed in $50 \%$ of women who have had childbirth, and often they are the starting point of the infection towards higher locations. In this there is an active infection, usually spread to the vagina and / or the uterine body, which can be caused by different germs. Pelvic inflammatory disease encompasses infections of the female upper genital tract. The importance of early diagnosis and its adequate treatment lies both in the complications in the acute phase and in the sequelae, which include chronic pain and sterility. All infections of the female genital tract present a symptomatology that may be common, such as dysuria, urinary frequency, vulvar pruritus, dyspareunia and leukorrhea. It is very difficult to distinguish these infections from each other only on the basis of the symptomatology, being absolutely necessary to be based on the exploration and the microbiological study to establish the diagnosis.

Keys words: Infections, bacterial vaginosis, mucopurulent cervicitis. Pelvic inflammatory disease. 


\section{Introducción.}

Las infecciones del aparato genital femenino, además de los problemas físicos y emocionales que ocasionan en las pacientes, constituyen una pérdida económica de proporciones apreciables al sistema de salud, tanto en las mujeres de países industrializados como en la población femenina de países en vías de desarrollo (Cutié, 2004).

Las manifestaciones clínicas de las infecciones del aparato genital femenino son muchas y variadas, desde una simple vaginitis hasta el shock séptico, con una serie de cuadros intermedios y progresivos como la endometritis, la salpingitis, los abscesos tubo-ováricos, la pelvi-peritonitis y la peritonitis, así como complicaciones durante la gestación, en el posparto y en el puerperio (Escalante, 2000).

En 2006, se calculó que 170 millones de personas en el mundo estaban infectadas por Trichomonas vaginalis. Las tasas de prevalencia entre las mujeres que residen en países en vías de desarrollo ascienden al 15\% o más, cifra que indica que es una de las enfermedades de transmisión sexual más comunes (Organización Mundial de la Salud, 2006).

En el (2009) la Organización Mundial de la Salud estimó, que anualmente unos 5000 millones de personas contraen alguna de las cuatro infecciones de transmisión sexual siguientes: tricomoniasis, clamidiasis, gonorrea, o sífilis. Un $28 \%$ de las mujeres de Latinoamérica mantienen un aseo inadecuado en las zonas íntimas, según los datos de la encuesta epidemiológica del 2008 de la higiene íntima femenina. Eso significa que el 28 por ciento tiene más probabilidades de padecer una infección vaginal. 
En el 2008 en México el tipo más frecuente de Vaginosis presentado en mujeres en edad fértil de 15 a 44 años de edad fue de Vaginosis Bacteriana. Se identificó con una prevalencia que oscila entre el 10\% - 40\% de acuerdo a diferentes estudios, y se considera la infección vaginal más frecuente. Ocurriendo en más del $30 \%$ de la población puede llevar a enfermedad inflamatoria pélvica y subsecuentemente a infertilidad, y a embarazadas a parto pretermino (Lopez, Bagnati, \& Trumper, 2001).

En el Ecuador un estudio realizado en población de Loja en el año 2009 arrojó una prevalencia del 34,7\% de infección vaginal, siendo la más frecuente la Vaginosis Bacteriana con su causante etiológico Gardnerella vaginilis continuándole la Candidiasis con su agente etiológico Cándida Albicans (Franco, 2009).

En la vagina se encuentra la denominada flora vaginal que es una barrera de protección constituida por diferentes especies de lactobacillus responsables de producir ácido láctico que mantiene el pH el cual protege el ecosistema vaginal, cuando existe un desequilibrio o alteración de la flora normal, por diversos factores que hacen que se produzca la colonización, proliferación y diseminación de microorganismos patógenos, se presenta una infección a nivel de la vagina con la consiguiente problemática para la mujer y los sistemas de salud (Laine, 2012).

Datos obtenidos de fuentes bibliográficas mencionan que existen una serie de factores que predisponen a las mujeres en edad fértil a adquirir dicha infección alterando el ecosistema normal de la vagina, como pueden ser: el uso de anticonceptivos, el uso de jabones o productos químicos para la limpieza o aseo de la zona genital, la automedicación de antibióticos, la diabetes y las practicas higiénicas inadecuadas del área genital y ano rectal (Salabarria, 2011). 
Fabián Zambrano-Loor; Nakin A. Veliz-Mero; María C. Guillen-Rivadeneira; Ronald A. Eche-Salvatierra; Jorge R. MacíasFernández; Tatiana A. Lino-Solís

En su gran mayoría las mujeres en edad fértil reinciden por más de una ocasión en infección vaginal debido a que presentan conocimiento erróneos de medidas higiénicas adecuadas para su área genital, convirtiéndose en muchas de ellas en recidivas y pudiendo llegar a producir diferentes complicaciones de acuerdo a los estilos de vida, generando ingentes gastos en el tratamiento de cada uno de los procesos infecciosos y sobre el tratamiento de las recidivas (Puentes, 2009).

La vaginosis bacteriana, que originalmente se le denominaba vaginitis inespecífica, hasta antes de 1955, cuando se informó que el Haemophilus vaginalis era el microorganismo causal. El nombre del microorganismo cambió después a Corynebacterium vaginale y posteriormente a Gardnerella vaginalis en honor a Gardner y Duke que trabajaron para descubrir este microorganismo (Biswas, 2000).

La vaginosis bacteriana no es considerada como una vaginitis, sino como alteración de la flora vaginal bacteriana normal donde hay una reducción de los lactobacilos productores de peróxido de hidrógeno y un incremento de prevalencia y concentración de Gardnerella vaginalis, Mycoplasma hominis y los anaerobios: Mobiluncus sp, Prevotella sp, Bacteroides sp. y Peptostreptococcus. Esta entidad ocasiona un flujo homogéneo, con olor fétido característico a "pescado". La vaginosis bacteriana es la causa más común de infección vaginal en mujeres en edad reproductiva y hasta un $50 \%$ de las pacientes pueden cursar asintomáticas (Center for Disease Control and Prevention, 2001).

La cervicitis es otra de las infecciones que afectan al aparato genital femenino, en mujeres en edad fértil y con vida sexual activa en cualquier época de su vida; (Peláez \& Mendoza J. 2012) refieren que "corresponden a infecciones, fundamentalmente bacterianas, del conducto endocervical; son frecuentes y están causadas, fundamentalmente, por un germen de transmisión sexual 
(Chlamydia trachomatis, Neisseria gonorrhoeae) o por un patógeno de la flora vaginal (Gardnerella vaginalis) “. La Trichomona vaginalis, Cándida albicans y el Virus del herpes simple son otros gérmenes, asociados en menor proporción a la inflamación del cuello uterino (Nuñez, 2002).

Se ha descrito que cada vez hay un número mayor de pacientes con cervicitis por C. trachomatis no investigadas rutinariamente y que quizás este hecho sea el que ocasiona algunos de los fracasos terapéuticos actuales. Este microorganismo es capaz de desencadenar otros padecimientos, la mayoría con graves repercusiones en la fertilidad, tales como la enfermedad pélvica inflamatoria (EPI) y obstrucción tubárica subsecuente, esta enfermedad tiene importancia en sí, pero es aún mayor si se tiene en cuenta que las alteraciones que pueden producir son a menudo causas de infertilidad, si no absoluta, al menos relativa (Center for Disease Control and Prevention, 2001).

La cervicitis es uno de los principales factores de riesgo para cáncer de cuello de útero y esterilidad con frecuencia son asintomáticas pero pueden llegar a constituir el punto de partida de una infección genital alta como la Enfermedad Pélvica Inflamatoria (E.P.I).

La Enfermedad Pélvica Inflamatoria (E.P.I) comprende las alteraciones inflamatorias e infecciosas que afectan los órganos genitales situados en la pelvis menor. Hernández (2010) cita que * la mayoría de los casos de enfermedad inflamatoria pélvica aguda están relacionados con enfermedades de transmisión sexual. Cada año miles de mujeres experimentan un episodio de enfermedad inflamatoria pélvica aguda (EIP) aguda y estas son sometidas a un creciente riesgo de molestias crónicas en el hemiabdomen inferior, embarazo ectópico, dolores por adherencias, infertilidad tubárica. 
Fabián Zambrano-Loor; Nakin A. Veliz-Mero; María C. Guillen-Rivadeneira; Ronald A. Eche-Salvatierra; Jorge R. MacíasFernández; Tatiana A. Lino-Solís

Aproximadamente un $12 \%$ de mujeres se convierten en infértiles después de un simple episodio, casi un $25 \%$ después de dos episodios y casi un $50 \%$ después de tres episodios. Otras secuelas asociadas son la dispareunia, el piosálpinx, los abscesos tuboováricos y adherencias pélvicas y muchas de ellas requerirán intervenciones quirúrgicas (Barie, Hydo, \& Eachempati, 2004).

En la práctica clínica, las infecciones vaginales se diagnostican de acuerdo a la sintomatología y las características del flujo vaginal y en la mayoría de las veces se inician un tratamiento empírico. Sin embargo, es importante diagnosticar y tratar oportunamente estas entidades pues a pesar de ser benignas puede dar lugar a complicaciones graves (Hillier \& Nugente, 2005).

\section{Metodología.}

Para lograr el objetivo de este estudio, se ha realizado una revisión narrativa de la literatura en las siguientes bases de datos: REDALYC, PUBMED y SCIELO, misma que está constituida por artículos originales, presentación de casos que en conjunto constituyen un valioso aporte académico y científico, descrito en el presente artículo.

\section{Desarrollo.}

\section{Vaginosis Bacteriana}

Bankowski et al. (2005) Indican que la Vaginosis Bacteriana es una enfermedad que ocurre en las mujeres, en la cual el equilibrio de la flora bacteriana normal en la vagina se ve alterado y en su lugar ciertas bacterias crecen de manera excesiva. En ocasiones, va acompañada de flujo vaginal, mal olor, dolor, picazón o ardor. 
Son muy pocos los datos que se han logrado obtener sobre la fisiopatología de la Vaginosis Bacteriana, por lo que no se ha podido establecer aún un método de diagnóstico y tratamiento adecuados. Recientemente se han comenzado a dilucidar los mecanismos involucrados en la aparición y la evolución de la vaginosis bacteriana (Hawes, y otros, 2006).

Los conceptos actuales sobre el origen polibacteriano de la enfermedad y el enfoque acertado de estas comunidades microbianas como un frágil ecosistema, caracterizado por una dependencia nutricional con complejas redes tróficas, donde existe una simbiosis y antibiosis marcada, encuentran cada vez más adeptos entre los conocedores del tema (Zhou, y otros, 2007).

Spiegel (2002) menciona que las mujeres con vaginosis bacteriana tienen pérdida de lactobacilos vaginales y una proliferación concomitante de bacterias anaeróbicas y facultativas. Varias bacterias han sido implicadas en la vaginosis bacteriana, como Gardnerella vaginalis y Mobiluncus curtisii, pero estas especies también se encuentran en sujetos que no tienen vaginosis bacteriana y, por lo tanto, no son marcadores específicos de la enfermedad.

Al menos tres de los siguientes cuatro elementos deben estar presentes para cumplir con los criterios clínicos de Amsel et al. (2003) para la vaginosis bacteriana: flujo vaginal delgado, homogéneo y lechoso; $\mathrm{pH}$ del fluido vaginal mayor que 4.5; una prueba de olor positivo (es decir, la producción de un olor a pescado cuando se agrega 10 por ciento de hidróxido de potasio a un portaobjetos que contiene fluido vaginal); y las células clave ( $>20$ por ciento de las células epiteliales con bacterias adherentes) en el examen microscópico del fluido vaginal.

La transmisión sexual ha sido implicada como un factor de riesgo debido a que esta enfermedad raramente se encuentra en mujeres que no han experimentado relaciones sexuales. En general, varias actividades humanas normales se asocian a una desestabilización de las comunidades 
Fabián Zambrano-Loor; Nakin A. Veliz-Mero; María C. Guillen-Rivadeneira; Ronald A. Eche-Salvatierra; Jorge R. MacíasFernández; Tatiana A. Lino-Solís

microbianas vaginales, lo que puede redundar en una mayor vulnerabilidad: actividad sexual frecuente, múltiples compañeros sexuales, sexo oral receptivo frecuente, mujeres homosexuales monógamas, empleo de duchas y espermicidas (Gonzales, Mota, Ortiz, \& Ponce, 2015).

De acuerdo a la terapéutica que indica el Ministerio de Salud Pública del Ecuador (2014), la paciente con referencia de descarga vaginal anormal con bajo riesgo de transmisión sexual y manifestaciones clínicas leves, está indicado iniciar tratamiento empírico, de acuerdo a las características clínicas etiológicas. En mujeres no embarazadas con síntomas característicos de la Vaginosis bacteriana, exámenes y otras pruebas se pueden omitir y el tratamiento empírico se puede iniciar.

Se debe dar tratamiento a mujeres con Vaginosis Bacteriana cuando:

- Sean Sintomáticas

- Asintomáticas que serán programadas para procedimientos quirúrgicos

- $\quad$ Asintomáticas que deseen tratarse

El (Ministerio de Salud Publica del Ecuador, 2014) Indican para el tratamiento de vaginosis bacteriana lo siguiente:

- Metronidazol 500 mg vía oral dos veces al día por 7 días;

- Metronidazol un óvulo de 500mg diario intravaginal por 7 días.

Como tratamiento alternativo están:

- Clindamicina $300 \mathrm{mg}$ oral dos veces al día por 7 días 
- Clindamicina 5 gramos (un aplicador lleno) intravaginal durante 7 días.

Bereck (2004) indica que dentro de las complicaciones de la Vaginosis Bacteriana se encuentran las siguientes: enfermedad inflamatoria pelviana, enfermedades de transmisión sexual (incluyendo clamidia, gonorrea, herpes, VIH) dolor pelviano crónico, infertilidad, endometritis postcesárea o post-parto, sangrado uterino anormal, salpingitis, cervicitis, particularmente en un $60 \%$ de casos asociada a cervicitis severa.

\section{Cervicitis}

Se conceptualiza como la inflamación aguda o crónica de las glándulas endocervical, o del ectocervix. Fernández (2007) la distingue en dos formas: Cervicitis aguda: caracterizada por la infiltración de polimorfonucleares bajo el epitelio de superficie y rodeando las hendiduras glanduliformes, acompañada de dilatación y congestión de los vasos sanguíneos. Cervicitis crónica: que se traduce en una marcada infiltración linfoplasmocitaria, acompañada de una proliferación, más o menos marcada del tejido conectivo que puede conducir a una hipertrofia adenomatosa.

La Chlamydia trachomatis es el microorganismo aislado con mayor frecuencia, seguido de Neisseria gonorrhoeae, Herpes simple y Tricomona vaginalis, estos dos últimos producen una exocervicitis, Chlamydia y gonococo infectan el endocérvix. El diagnóstico etiológico se establece mediante cultivos del exudado endocervical, que debe obtenerse tras la limpieza previa del orificio externo del cérvix (Grases, 2012).

Las cervicitis de larga evolución pueden acompañarse de intenso infiltrado crónico con formación de centros germinales. Este cuadro histológico, denominado cervicitis crónica folicular o linfocítica, se caracteriza en el extendido celular por la presencia de abundantes linfocitos maduros, 
Fabián Zambrano-Loor; Nakin A. Veliz-Mero; María C. Guillen-Rivadeneira; Ronald A. Eche-Salvatierra; Jorge R. MacíasFernández; Tatiana A. Lino-Solís

células linfoides centro foliculares y macrófagos con partículas fagocitadas, se ha descrito también su asociación a infección por Chlamydia y Citomegalovirus. Conviene tener en cuenta este cuadro citológico para evitar errores diagnósticos con linfomas o carcinomas indiferenciados (Bethesda, 2009).

La Organización Mundial de la Salud (2005) propone los siguientes factores de riesgo que deben ser interrogados durante la anamnesis:

- $\quad$ Edad de 21 años o menos.

- $\quad$ Estado civil soltera

- $\quad$ Más de una pareja sexual en los últimos tres meses.

- $\quad$ Nueva pareja sexual en los últimos tres meses

- $\quad$ Pareja actual que padece una Infección de Trasmisión Sexual

- $\quad$ Pareja que ha comenzado a utilizar condones recientemente.

Rodríguez (2010) ha determinado otros factores de riesgo tales como el consumo de drogas, el consumo de alcohol uso de anticonceptivos orales, no uso de preservativo, nivel educativo de la paciente, características raciales, Infecciones de Trasmisión Sexual o infecciones del tracto vaginal previas.

Las cervicitis suelen ser asintomáticas en su mayoría, cuando se manifiestan clínicamente lo suelen hacer en forma de leucorrea más o menos abundante, y con el aspecto típico del germen causante de la infección. Las formas crónicas suelen ser causantes de coitorragias (Perea, 2010). 
En otro estudio la dispareunia es un síntoma sensible para el diagnóstico de cervicitis y los signos de muco-pus cervical y friabilidad cervical si bien no son sensibles sí resultan altamente específicos por lo que su presencia al examen físico indica la presencia de infección cervical (Oliver, 2011).

Para afirmar que existe una cervicitis mucopurulenta, el exudado del cérvix obtenido con una torunda de algodón blanco, tras una primera limpieza de la mucosidad, debe manchar la torunda de color amarillento o verdoso extendido sobre el portaobjetos, visto al microscopio (x 1.000) debe contener al menos 10 polimorfonucleares por campo, en 5 campos no adyacentes observados de forma consecutiva (Perea, 2010).

Está indicada la azitromicina $1 \mathrm{~g}$ en dosis única o doxiciclina $100 \mathrm{mg}$ cada 12 horas por vía oral durante 7 días. Como régimen alternativo podemos emplear levofloxacino $500 \mathrm{mg}$ al día durante 7 días. Tanto la doxiciclina como el levofloxacino están contraindicados en la infección en mujeres embarazadas, la azitromicina es eficaz y segura. Por los riesgos de infección del neonato debe repetirse el cultivo a las tres semanas de finalizado el tratamiento (Perea, 2010).

En un estudio realizado sobre tratamientos adicionales incluyen antibióticos secundarios, tratamientos hormonales, hidrocortisona, vaginal de nitrato de plata, crioterapia, y el procedimiento de escisión electro-quirúrgica con bucle. Las tasas de curación fueron 57,9\% con antibióticos, 50\% con la hormona del tratamiento, $0 \%$ con hidrocortisona, $100 \%$ con nitrato de plata, $0 \%$ con crioterapia, y 100\% con el bucle de procedimiento de escisión electroquirúrgica. De las primeras 61 mujeres, el 93,4\% fueron finalmente curado (Organizacion Mundial de la Salud, 2005).

\section{Enfermedad pélvica inflamatoria}


Fabián Zambrano-Loor; Nakin A. Veliz-Mero; María C. Guillen-Rivadeneira; Ronald A. Eche-Salvatierra; Jorge R. MacíasFernández; Tatiana A. Lino-Solís

La Enfermedad Pélvica Inflamatoria (EPI) es la infección del tracto genital superior en las mujeres que involucra al útero, las trompas de Falopio, y los ovarios. La enfermedad pélvica inflamatoria no solo tiene como consecuencias problemas biológicos, sino también de tipo social, laboral y hasta en el ámbito económico (Herrera, y otros, 2016).

Peláez (2012) sustenta que la etiología en el 85\% de los casos de EPI son patógenos de transmisión sexual comunes, como Chlamydia y la Neisseria; y con menos frecuencia, por la gardnerella vaginalis, streptococcus agalactiae, haemofphilus influenzae. Menos del 15\% de los casos no fueron transmitidos por vía sexual, sino por colocación de DIU, duchas vaginales o por procedimientos quirúrgicos genitales previos. La adolescencia es la etapa más propensa para padecer EPI; esta enfermedad prevalece en mujeres entre 25 y 45 años de edad y disminuye en aquellas que tienen de 50 años en adelante.

La Enfermedad Pélvica Inflamatoria se presenta a través de varios síntomas, en el 95\% de los casos, el más común es el dolor abdominal que suele localizarse en los cuadrantes inferiores. Este puede presentarse de forma bilateral y con una intensidad variable que aumenta con el coito (Román, 2009). En el 55\% de los casos, también se pueden presentar otras molestias, como el dolor tras la movilización del cérvix, útero o anexos, durante el examen ginecológico. Aproximadamente, el $75 \%$ de las pacientes tienen leucorrea; por lo cual, pueden tener sangrado genital anormal, fiebre, náusea, vómito o dispareunia. Las mujeres con Chlamydia tienden a padecer otras afecciones, como salpingitis y, como secuelas de la enfermedad, se presentan adherencias y hasta infertilidad (Román \& Martínez, 2009).

La Enfermedad Pélvica Inflamatoria se clasifica: según su evolución clínica en aguda y crónica; por su etiología en endógeno o exógena; por su origen primario o secundario; por los 
estadios clínicos en salpingitis, endometritis, absceso tuvo-ovárico o peritonitis difusa (Larraburo, 2014).

La EPI aguda dura menos de 30 días, el diagnóstico es clínico. La infección se produce por ascensión de microorganismos, desde el cuello del útero o desde la vagina al endometrio, trompas y anexos. Por el contrario, la EPI crónica dura más de 30 días y se produce por Mycobacterium tuberculosis o alguna de las especies de actinomices. Esta presenta dolor pélvico recurrente crónico y estos síntomas son más comunes luego del primer episodio (Robert, Brunham, Sami, Gottlieb, \& Jorma, 2015).

La sensibilidad del diagnóstico clínico es del 65 al 90\%; pero, debido a las secuelas graves que se pueden producir si el tratamiento se retrasa o no se da, este diagnóstico presuntivo es suficiente para justificar la terapia antimicrobiana empírica para la EPI. Incluso, los pacientes cuyos resultados son un mínimo o sutil indicio de esta infección deben sometidos a un tratamiento para evitar las posibles consecuencias de la enfermedad (Saona, 2007)

El diagnóstico y tratamiento oportuno de la Enfermedad Pélvica Inflamatoria, en la mayoría de los casos, reduce los riesgos de las complicaciones. Sin embargo, no siempre se pueden evitar las secuelas de la Enfermedad Pélvica Inflamatoria. Se presume que las adherencias y cicatrices que deja la infección son la causa del dolor abdominal crónico, la infertilidad y la posibilidad de un embarazo ectópico. Estas condiciones de salud representan para las pacientes el incumplimiento de sus roles personales normales (Pacheco J, 2015). El conocimiento es el factor principal para protegerse de la EPI; por esta razón, es importante mantener una conducta preventiva mediante controles médicos adecuados, cuidados luego de un procedimiento quirúrgico genital, entre otros. 
Fabián Zambrano-Loor; Nakin A. Veliz-Mero; María C. Guillen-Rivadeneira; Ronald A. Eche-Salvatierra; Jorge R. MacíasFernández; Tatiana A. Lino-Solís

Del mismo modo, es importante conocer las causas, efectos y las consecuencias en la salud que puede dejar esta enfermedad (Pacheco, 2018).

Bolio et al. (2012) Menciona como factores de riesgo. Edad y promiscuidad sexual, la E.P.I es significativamente más frecuente por debajo de los 30 años y el riesgo es especialmente elevado en adolescentes. Esto se ha relacionado con un mayor grado de promiscuidad sexual en edades jóvenes, bajo nivel socioeconómico, E.P.I previa, parto o aborto espontáneo y procederes invasivos en el aparato genital (aborto provocado, regulación menstrual, histerosalpingografia, insuflación tubárica, histerometría, legrado diagnóstico, colocación de DIU y su retiro, duchas vaginales y cirugías sobre el cuello uterino).

La Enfermedad Pélvica Inflamatoria afecta, altamente, a la salud y provoca consecuencias significativas en el ámbito: personal, familiar, laboral, social, y económico (Delgado, 2015). Si esta no es tratada a tiempo, puede causar infertilidad y este efecto se presenta en 1 de cada 10 pacientes con EPI leve aguda. También, puede provocar un incremento de embarazos ectópicos, a partir de los cuales el $99 \%$ de las pacientes quedan con dolores pélvicos crónicos. Estas afecciones requieren que la paciente siga un tratamiento intravenoso que demandan de más días de hospitalización, de acuerdo con los datos proporcionados por el Colegio Americano Obstetricia y Ginecología. (ACOG, 2016)

\section{Conflicto de Intereses}

Los autores declaran que no existen conflictos de intereses.

\section{Declaración de Contribución}

Todos los autores participaron en la búsqueda de información y en la redacción del artículo. 


\section{Bibliografía.}

Amsel, R., Totten, P., Spiegel, C., Chen, K., Eschenbach, D., \& Holmes, K. (2003). Vaginitis inespecífica: criterios diagnósticos y asociaciones microbianas y epidemiológicas. Am J Med , $14-22$.

Bankowski, B., Hearne, A., Lambrou, N., Fox, H., Wallach, E., \& Johns, H. (2005). Ginecología y Obstetricia. Madrid, España.

Barie, P., Hydo, L., \& Eachempati, S. (2004). Longitudinal outcomes of intra-abdominal infection complicated by critical illness. Surg Infect, 365-373.

Bereck, J. (2004). Ginecología de Novack. EDICUSA Ediciones culturales, S.A .

Bethesda, A. J. (2009). Fundamentos de ginecología. Panamericana.

Biswas, M. K. (2000). Vaginosos Bacteriana. Clinicas Obstetricas y Ginecologicas, 165-174.

Bolio, J., Antonio, K., \& Paoli, B. (2012). Husserl y la fenomenología trascendental: Perspectivas del sujeto en las ciencias del siglo XX. ,. Ed. Reencuentro, 20 - 29.

Center for Disease Control and Prevention. (2001). Guidelines for treatment of sexually transmitted diseases. .

Cutié, E. (2004). Infecciones de Transmisión Sexual. . En Obstetricia y Ginecolog' 'ia (págs. 391399). La Habana: Ciencias Médicas.

Delgado, V. (Marzo de 2015). Enfermedades Pélvicas Inflamatorias en mujeres de entre 14 y 54 años de edad que son atendidas en Solca de Esmeraldas en los primeros meses del año 2014. Obtenido de http// repositorio.pucese.edu.ec/bitstream/123456789/292/1/

Escalante, J. (2000). Infecciones Vulvovaginales. En Tratado de Obstetricia y Ginecología (págs. 239-240). New York: Mc. Graw Hill.

Franco, J. (2009). FACTORES DE RIESGO DE RECIDIVAS DE INFECCIONES EN MUJERES. Loja.

Gomez, F. (2007). PATOLOGÍA BENIGNA Y LESIONES PREMALIGNAS DEL CEERVIX. . En Obstetricia y Ginecologia. Granada.

Gonzales, A., Mota, R., Ortiz, C., \& Ponce, R. (2015). Factores de riesgo asociados a Vaginosis Bacteriana.

Grases, G. P. (2012). PATOLOGIA GINECOLOGICA: BASES PARA EL DIAGNOSTICO MORFOLOGICO. MASSON, 25.

Hawes, S., Hillier, S., Benedetti, J., Stevens, C., Koutsky, L., \& Wolner, H. P. (2006). Hydrogen peroxide-producing lactobacilli and acquisition of vaginal infections. Infect Dis, 1058-1063.

Hernandez, D. O. (2010). Enfermedad inflamatoria pélvica. REDALIC, 613-631.

Herrera, D., Gaus, D., Troya, C., Obregón, M., Guevara, A., \& Romero, S. (2016). Enfermedad pélvica inflamatoria (EPI). . Manual Médico SALUDESA, 22-23. 
Fabián Zambrano-Loor; Nakin A. Veliz-Mero; María C. Guillen-Rivadeneira; Ronald A. Eche-Salvatierra; Jorge R. MacíasFernández; Tatiana A. Lino-Solís

Hillier, S. L., \& Nugente, R. P. (2005). Association between bacterial vaginosis and preterm delivery of a low birth-weight infant. Pub Med.

Laine, J. (2012). Flora vaginal: un frágil equilibrio. Obtenido de http://salud.doctissimo.es/saludfemenina/higiene-intima/la-flora-vaginal-un-fragil-equilibrio.html

Larraburo, M. (2014). Enfermedad Pélvica Inflamatoria: generalidades y manejo terapéutico en las mujeres afectadas con este padecimiento. Médica de Costa Rica y Centro américa, 141 144.

Lopez, K., Bagnati, \& Trumper, E. (2001). Vaginosis Bacteriana/ Bacterial Vaginosis. Obtenido de http://bases.bireme.br/cgi

Ministerio de Salud Publica del Ecuador. (2014). Prevención, Diagnóstico y tratamiento de las Infecciones Vaginales. Ecuador.

Nuñez, N. (2002). Mycoplasma hominis y Ureaplasma urealyticum en diferentes patologías ginecológicas. Invest Clin, 9-24.

Oliver, D. M. (2011). LO QUE TODO GINECÓLOGO DEBERÍA SER CAPAZ DE VER. Servicio de Obstetricia y Ginecología. Hospital Universitario Virgen de las Nieves Granada.

Oraganizacion Mundial de la Salud. (2005). Guías para el tratamiento de las infecciones de transmisión sexual.

Organización Mundial de la Salud. (2006). Infecciones genitales de la mujer.

Organización Mundial de la Salud. (2009). Infecciones de transmisión sexual.

Pacheco, J. (septiembre de 2018). Enfermedad pélvica inflamatoria: introducción. Obtenido de http://spog.org.pe/web/revista/index.php/RPGO/article/view/1046

Peláez, J. C. (2012). Enfermedad inflamatoria pélvica y adolescencia. . Revista Cubana de Obstetricia y Ginecología., 64-79.

Perea, E. J. (2010). Infecciones del aparato genital femenino; vaginitis, vaginosis, y cervicitis. Medicine.

Puentes, E. M. (2009). Comportamiento del Síndrome de flujo vaginal en el Consultorio 16. Revista Cielo.

Robert, C., Brunham, M., Sami, L., Gottlieb, M., \& Jorma, M. (2015). Pelvic Inflammatory Disease. The New England Journal of Medicine, 2039-2048.

Rodríguez, H. A. (2010). Validez del diagnóstico sindrómico de cervicitis y flujo vaginal en mujeres en edad reproductiva, Bogotá-Colombia 2010. Colombia.

Román, A., \& Martínez, O. (2009). Enfermedad Inflamatoria Pélvica. En Fundamentos de Ginecología Sociedad Ecuatoriana de Ginecología y Obstetricia. , 175.

Salabarria, M. (2011). Factores de Riesgo de la Infección Vaginal. Obtenido de http://www.ilustrados.com/tema/8238/Factores-Riesgo-Infeccion-Vaginal.html

Spiegel, C. A. (2002). Vaginosis bacteriana. Clin Microbiol Rev, 485 - 502. 
Zhou, X., Brown, C., Abdo, Z., Davis, C., Hansmann, M., \& Joyce, P. (2007). Differences in the composition of vaginal microbial communities found in healthy Caucasian and black women. ISME J., 121-133 